\title{
In situ broadband acoustic measurements of age-0 walleye pollock and pointhead flounder in Funka Bay, Hokkaido, Japan
}

Kohei Hasegawa

Faculty of Fisheries Sciences, Hokkaido University, Japan, kohase@fish.hokudai.ac.jp

Naizheng Yan

Faculty of Fisheries Sciences, Hokkaido University, Japan

Tohru Mukai

Faculty of Fisheries Sciences, Hokkaido University, Japan

Follow this and additional works at: https://jmstt.ntou.edu.tw/journal

Part of the Fresh Water Studies Commons, Marine Biology Commons, Ocean Engineering Commons, Oceanography Commons, and the Other Oceanography and Atmospheric Sciences and Meteorology Commons

\section{Recommended Citation}

Hasegawa, Kohei; Yan, Naizheng; and Mukai, Tohru (2021) "In situ broadband acoustic measurements of age-0 walleye pollock and pointhead flounder in Funka Bay, Hokkaido, Japan," Journal of Marine Science and Technology. Vol. 29: Iss. 2, Article 2. DOI: $10.51400 / 2709-6998.1076$

Available at: https://jmstt.ntou.edu.tw/journal/vol29/iss2/2

This Research Article is brought to you for free and open access by Journal of Marine Science and Technology. It has been accepted for inclusion in Journal of Marine Science and Technology by an authorized editor of Journal of Marine Science and Technology. 


\title{
In situ Broadband Acoustic Measurements of Age-0 Walleye Pollock and Pointhead Flounder in Funka Bay, Hokkaido, Japan
}

\author{
Kohei Hasegawa*, Naizheng Yan, Tohru Mukai
}

Faculty of Fisheries Sciences, Hokkaido University, Hokkaido, Japan

\begin{abstract}
Measurements of the broadband acoustic backscattering from fish should improve acoustic discrimination between species. The pulse compression processing of broadband systems can be used to measure acoustic backscattering with high range resolution and improve signal-to-noise ratio. This may increase opportunities for in situ target strength (TS) measurements, the preferred method of collecting TS data. To evaluate the availability of TS spectra for acoustic discrimination, three Simrad EK80 wideband transceivers and split-beam transducers of 70, 120, and $200 \mathrm{kHz}$ were used to collect in situ frequency responses of TS from age-0 juvenile walleye pollock and pointhead flounder, a swim-bladderless flat-fish, distributed in and around Funka Bay, Hokkaido, Japan. The single echoes were extracted from backscattering data, and the TS spectra of the two species were obtained. However, processing of the broadband acoustic data is under discussion. To ensure the reliability of our data, the TS spectra of standard targets were also calculated. The measured TS spectra of the standard targets were close to the theoretical TS spectra. The individual TS spectra of two species included complex frequency response; however, the mean TS spectrum was relatively stable. The different characteristics of the frequency responses observed for the two species were in good agreement with reported observations. The results available for the acoustic discrimination were similar to the multi-frequency method, which uses two or more single frequencies. The raw $\mathrm{TS}$ spectra should aid in not only discriminating between species but also estimating the size of the fish.
\end{abstract}

Keywords: Broadband echosounder, Target strength, Acoustic discrimination

\section{Introduction}

$\mathrm{T}$ arget strength (TS), which refers to the acoustic intensity response from an organism, is a critical parameter for acoustic abundance estimations. As TS is complicated by morphological and physiological factors, measuring TS in a natural condition (i.e., in situ TS) including these factors is regarded as the preferred method [1,2]. However, detection of a single-target echo in a field is generally limited by experimental conditions. Echoes from individual fish in schools that are dense or a long distance from a transducer are difficult to extract because of the limitation of system resolution. In addition, echoes from multiple fish may be misdetected as single echoes in such conditions, which causes overestimation of TS [3]. To avoid using data including such bias, indexes of the possibility of misdetection were proposed [4,5]. Low signal-to-noise ratio (SNR) also causes overestimation due to missing fish whose backscattering is weak. The bias is caused by weak echoes received at the periphery of the transducer directivity. Therefore, a cut-off angle or threshold of beam compensation has been applied to filter inappropriate data $[4,6,7]$. 
Discrimination between species by means of acoustic data is a challenge in this field [8]. The frequency response is an important characteristic of the backscattering utilized for acoustic discrimination. The multi-frequency method, using two or more single frequencies, is an effective discrimination method [9,10]. However, although it can discriminate efficiently between organisms with different acoustic characteristics (e.g., swim-bladder fish and euphausiids), it has difficulty discriminating between species with similar acoustic characteristics using the discrete frequency response [11].

A broadband acoustic system using a frequencymodulated chirp signal provides high range resolution and improved SNR data via pulse compression processing [12-14]. In addition, the backscattering data obtained from such systems include the responses relative to consecutive widerange frequency bands. Therefore, a broadband system has the potential to collect a large number of broadband frequency responses of TS in a field, and it is expected to improve the quality of the acoustic discrimination. Several studies have reported on acoustic discrimination using broadband systems $[15,16]$. However, they used volume backscattering strength (SV) only and did not consider the frequency response of TS from an individual fish in a school.

In this study, to measure and process broadband in situ TS data, backscattering from walleye pollock (Gadus chalcogrammus) and pointhead flounder (Cleisthenes pinetorum) was collected with a broadband echosounder in Funka Bay, located in Southern Hokkaido, Japan. Pacific stocks of walleye pollock distributed around the Pacific coastal area of the Tohoku region and Hokkaido are the most abundant in Japan. Funka Bay is an important spawning and nursery ground for the Pacific stocks [17]. Therefore, from winter to early summer, age0 juvenile walleye pollock can be observed around Funka Bay, and the distributions of their predators overlap. One of the major predators of walleye pollocks around Funka Bay is the pointhead flounder, which is a swim-bladderless flatfish and an important fishery resource in Northern Japan. As schools of pointhead flounder are observed in midwater during the daytime, discrimination between the two species is necessary for the estimation of their abundance.

Yan et al. [18] revealed the difference in acoustic characteristics between the two species using the relative frequency response of the volume backscattering strength between 38 and $200 \mathrm{kHz}$ (i.e., $\left.\Delta S V_{200-38}\right)$, and succeeded in discriminating between schools of the two species. However, the TS of the two species was difficult to measure because they formed schools. This condition may be improved by measuring the backscattering at higher resolutions. This study addresses the broadband acoustic measurement of in situ TS of the two species around Funka Bay, and evaluates the qualities and availability of the broadband frequency response of in situ TS for acoustic discrimination.

\section{Materials and Methods}

\subsection{Study sites and periods}

From April to June 2019, broadband acoustic measurements were carried out during surveys in Funka Bay on board T/S Ushio-Maru (Hokkaido University). The measurement sites were in and around the mouth of Funka Bay (Fig. 1), determined by the capture results of a towed frame-type midwater trawl net (FMT, $2 \mathrm{~m}^{2}$ mouth opening and $1.5 \mathrm{~mm}$ mesh opening), vertical towed ring net (80$\mathrm{cm}$-diameter mouth opening and $0.5 \mathrm{~mm}$ mesh opening), or rod fishing (Table 1). The pointhead flounder was measured once during the daytime (April 12), and the juvenile walleye pollock was measured thrice at night (April 12, May 9, and June 6). All acoustic data were collected with the ship drifting.

\subsection{Echosounder settings and calibration}

Simrad EK80 wideband transceivers (WBT) and split-beam transducers with nominal frequencies of 70,120 , and $200 \mathrm{kHz}$ were used. The 120 and $200 \mathrm{kHz}$ split-beam transducers (ES120-7C and ES200-7C) were originally equipped on UshioMaru. The two-frequency data were collected in April and May but were not used on June 6 because of the limitation of the rental period of the WBTs (Table 1). Meanwhile, the $70 \mathrm{kHz}$ data were collected by equipping the $70 \mathrm{kHz}$ transducer (ES707C) on the side of the ship, conditions permitting. When two or more frequencies were used simultaneously, the sequential mode was used to avoid crosstalk [19]. To collect broadband acoustic data, the upchirp signal of FM mode was used and the pulse width was set at $2.048 \mathrm{~ms}$ for all frequencies. The transmitted signal can be selected with "fast" or "slow" ramping mode, using different Hann window lengths $[19,20]$. The slow ramping signal is applied to the window function over the entire signal to suppress range sidelobes generated by the pulse compression processing. However, the slow ramping signal reduces the bandwidth and the 


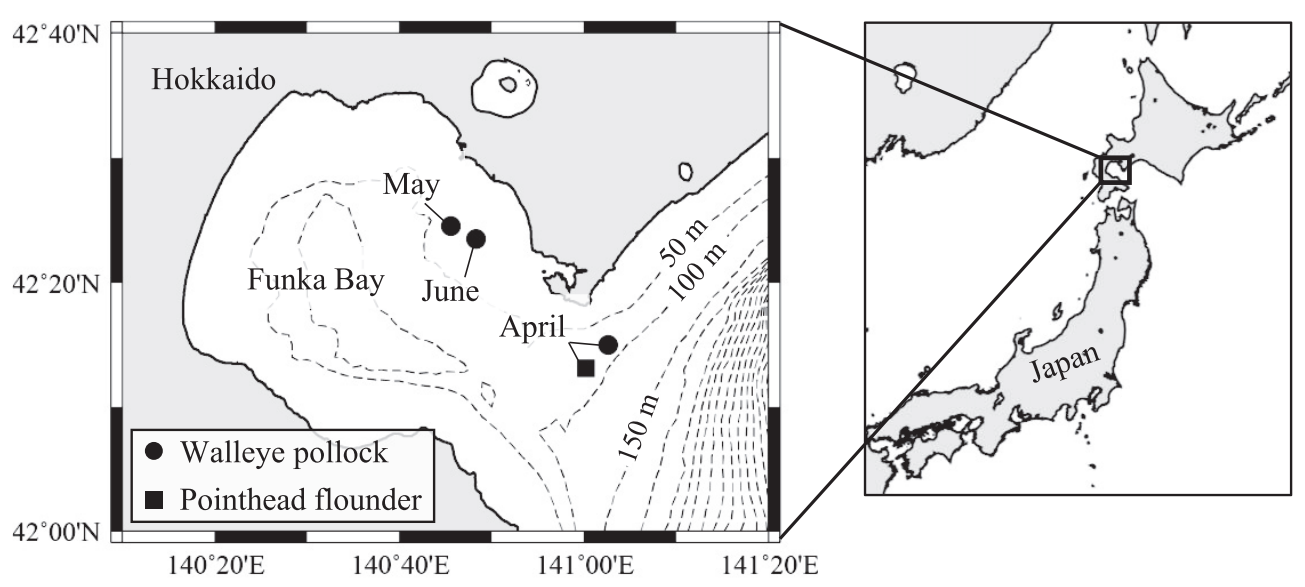

Fig. 1. Sites at which the broadband acoustic measurements were carried out.

Table 1. Dates of acoustic measurements and methods used for verification of the species.

\begin{tabular}{lllll}
\hline Target species & Date & Time & Verification & Frequency used (kHz) \\
\hline Pointhead flounder & April 12 & $16: 30-17: 10$ & Rod fishing & $70,120,200$ \\
Walleye pollock & April 12 & $19: 30-19: 40$ & FMT & 120,200 \\
Walleye pollock & May 9 & $21: 45-21: 55$ & Ring net & $70,120,200$ \\
Walleye pollock & June 6 & $21: 10-21: 20$ & FMT & 70 \\
\hline
\end{tabular}

range resolution due to cutting a part of the signal by the window function. The slow ramping signal is effective to detect targets near the seabed that cause high level range sidelobes [20]. The fast ramping signal has a broader bandwidth but has higher level range sidelobes. In this study, the fast ramping signal was used because the targets were not distributed near the seabed and the spectral characteristics of the targets as broad as possible are important.

All echosounders were calibrated using standard targets (spheres made from tungsten carbide with $6 \%$ cobalt binder), according to [21,22]. The FM70 $\mathrm{kHz}$ was calibrated by a $25 \mathrm{~mm}$ diameter sphere, FM120 kHz by a $22 \mathrm{~mm}$ diameter sphere, and FM200 $\mathrm{kHz}$ by $22 \mathrm{~mm}$ and $38.1 \mathrm{~mm}$ diameter spheres. However, some frequency bands of the transmitting signals could not be calibrated because there were some dips in the TS frequency responses of the spheres. Considering the effect of the window function applied to the received signal, the frequency bands used for analyses were also cut by $10 \mathrm{kHz}$ from the start and end frequencies of the transmitting bands (Table 2).

\subsection{Acoustic data analysis}

The scattering layers at 5-20 m depth appearing at night were treated as schools of juvenile walleye pollock (Fig. 2), validated by the capture results of
Table 2. Frequency band $(\mathrm{kHz})$ settings of WBTs.

\begin{tabular}{llll}
\hline Nominal frequency & Transmitting & Calibrated & Analyzed \\
\hline 70 & $45-90$ & $45-90$ & $55-80$ \\
120 & $90-170$ & $90-150$ & $100-150$ \\
200 & $160-260$ & $160-220$ & $170-220$ \\
& & $230-240$ & $230-240$ \\
\hline
\end{tabular}

the FMT and ring net. However, various scattering layers were observed in the measurement on May 9 (Fig. 3). The data in the scattering layer at $15-20 \mathrm{~m}$ were not used because they included higher SV values at 120 and $200 \mathrm{kHz}$ than at $70 \mathrm{kHz}$, which were assumed to be due to zooplanktons. Pointhead flounder schools form a "patchy echo" in midwater during the daytime [18]. The schools in red circles in Fig. $2 a$ are consistent with such observation and we actually captured pointhead flounder by rod fishing. Therefore, we processed these echoes as pointhead flounder.

Acoustic data were processed with Echoview version 10 (Echoview Software). Single-target echoes were extracted from the acoustic data with single target detection, and the frequency responses of TS were calculated. In the processing by Echoview, the compressed pulse power was used to determine candidate pulse-peaks and the normalized pulse length (the range within $6 \mathrm{~dB}$ relative to the peak power) was calculated. The normalized pulse length, the standard deviation of the phase difference between alongship and athwartship in all 
(a) April 12

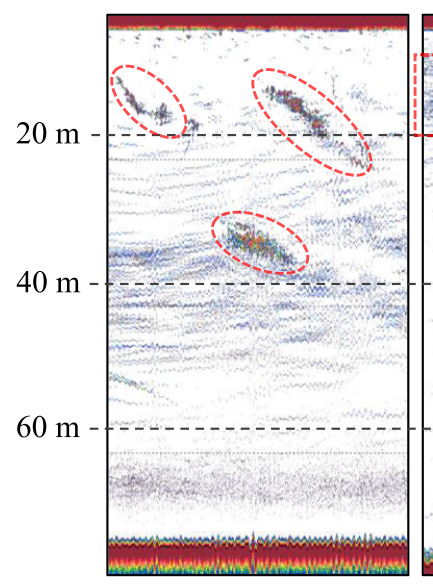

(b) April 12

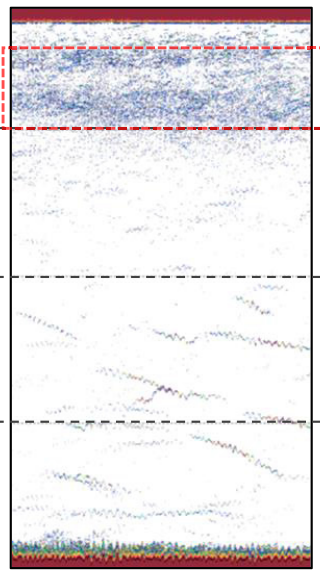

(c) June 6

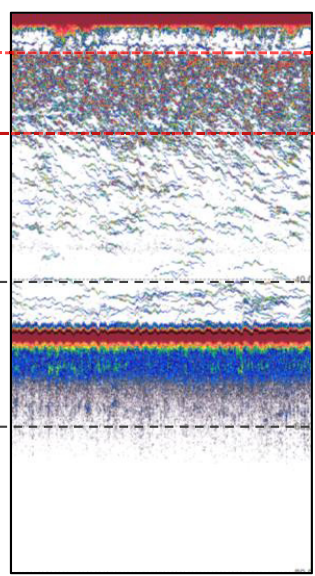

$-39 \mathrm{~dB}$

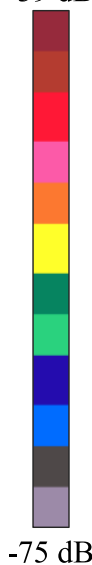

Fig. 2. Echogram displays including (a) pointhead flounder, and $(b, c)$ walleye pollock. SV values at FM $120 \mathrm{kHz}$ are shown in (a, b), and at FM $70 \mathrm{kHz}$ in (c).

samples, and the beam compensation level were used to judge if the samples satisfy the conditions for the detection. Finally, if the TS calculated from the peak power was higher than the threshold set by a user, the samples were detected as a single echo. The TS threshold was set for each measurement (Table 3), and other criteria for processing were set as follows: normalized pulse duration (the acceptable range of the normalized pulse length) $=0.6-1.3$, and beam compensation $=6 \mathrm{~dB}$. The parameters for the signal target detection algorithm were determined empirically. However, the processing of broadband acoustic data by Echoview is under development. Therefore, to evaluate the quality of our results, the TS spectra of the standard targets were calculated from the backscattering data during the calibration, and the predicted TS spectra of all spheres were compared with the measurement data. The TS spectra of the $22 \mathrm{~mm}$ and $38.1 \mathrm{~mm}$ diameter spheres were obtained by FM120 and FM200 kHz, and the TS spectra of the $25 \mathrm{~mm}$ diameter sphere were obtained by FM70 kHz. The window size for fast Fourier transform (FFT length) has a significant effect on the results [19]. Therefore, to determine the FFT length to use in this study, the TS spectra were calculated using several different FFT lengths. (a) $70 \mathrm{kHz}$

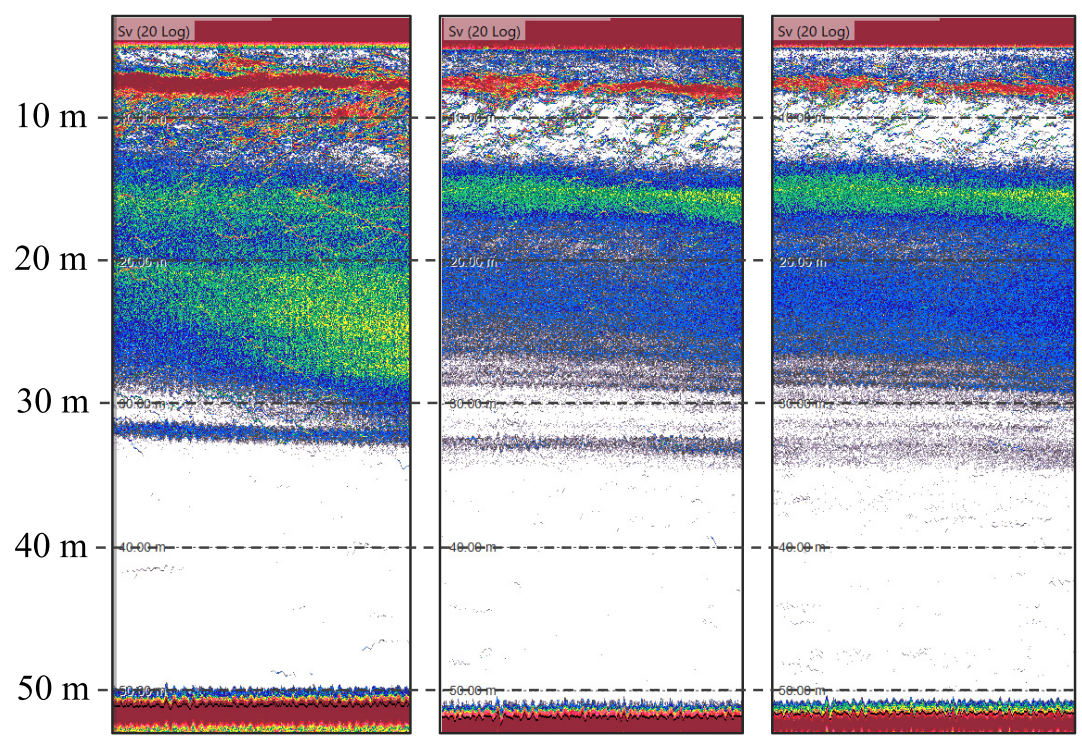

$-39 \mathrm{~dB}$

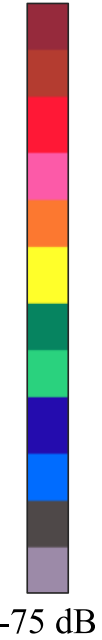

Fig. 3. Echogram displays (SV) of three FM frequencies observed on May 9. 
Table 3. Settings for extracting single echo.

\begin{tabular}{lllll}
\hline Target species & Date & TS threshold & $\begin{array}{l}\text { Normalized } \\
\text { pulse duration }\end{array}$ & $\begin{array}{l}\text { Maximum beam } \\
\text { compensation }\end{array}$ \\
\hline Pointhead flounder & April 12 & $-55 \mathrm{~dB}$ & $0.6-1.3$ & $6 \mathrm{~dB}$ \\
Walleye pollock & April 12 & $-75 \mathrm{~dB}$ & & \\
Walleye pollock & May 9 & $-70 \mathrm{~dB}$ & & \\
Walleye pollock & June 6 & $-70 \mathrm{~dB}$ & & \\
\hline
\end{tabular}

To ascertain if the single echoes were obtained in the appropriate condition, the number of fish in the reverberation volume $N_{\mathrm{v}}$, which is determined from Equation (1) [4], was used.

$N_{\mathrm{v}}=\frac{1}{2} c \tau \psi r^{2} n$

where $c$ is the speed of sound $(\mathrm{m} / \mathrm{s}), \tau$ is the pulse width (s), $\psi$ is the equivalent beam angle (steradians), $r$ is the range $(\mathrm{m})$, and $n$ is the fish distribution density $\left(1 / \mathrm{m}^{3}\right)$ derived from the mean volume backscattering coefficient $\langle S v\rangle$ and mean backscattering cross section $\left\langle\sigma_{\mathrm{bs}}\right\rangle$ :

$n=\frac{\langle S v\rangle}{\left\langle\sigma_{\mathrm{bs}}\right\rangle}$

$\left\langle\sigma_{\mathrm{bs}}\right\rangle=10^{\frac{<T S\rangle}{10}}$

The nominal frequencies $(70,120$, and $200 \mathrm{kHz})$ of the $N_{\mathrm{v}}$ values were calculated by extracting SV values at the nominal frequencies from the SV spectra. The predicted mean TS were derived from the mean fish length (fork length $(F L)$ for the walleye pollock and total length (TL) for the pointhead flounder) obtained from the capture results and the TS normalized by fish length $(<T S\rangle=20 \log (F L$ or $\left.T L)+T S_{\mathrm{cm}}\right) \cdot T S_{\mathrm{cm}}=-66.0 \mathrm{~dB}$ was used for the walleye pollock [23] at all frequencies, and $T S_{\mathrm{cm}}$ $(70 \mathrm{kHz})=-76.6 \mathrm{~dB}$ and $T S_{\mathrm{cm}}(120 \mathrm{kHz}$ and $200 \mathrm{kHz})=-72.3 \mathrm{~dB}(\mathrm{~N}$. Yan., unpublished data; noting that the $T S_{\mathrm{cm}}$ at $200 \mathrm{kHz}$ is not in the confident range of the $T L$ by wave length $(T L / \lambda)$ ) were used for the pointhead flounder. The equivalent beam angle at the nominal frequencies was used for $\psi$. The pulse length $(c \tau / 2)$ must be considered for the broadband data because the received signal was processed by the matched filter, shortening the pulse length. In addition, FFT length also affects the data length involved in the sampling volume. In this study, FFT length was considered as the preferred value for the pulse length because the final sampling volume and the range resolution were determined by the FFT length rather than the compressed pulse length. The $N_{\mathrm{v}}$ in the measurement of the walleye pollock was calculated for $5 \mathrm{~m}$ thick layers (5-10, 10-15, and 15-20 m). In addition, the $N_{\mathrm{v}}$ in the dense layer observed on May 9 was also calculated (Fig. 3). The $\langle S v\rangle$ of walleye pollock was derived from 100 pings of SV data. The $N_{v}$ in the measurement of the pointhead flounder was calculated for each school. The 10-30 pings of SV data were used for deriving $\langle S v\rangle$ depending on the size of the school.

As in situ TS varies relative to the size distribution and the angle distribution of the targets, TS values averaged in linear scale were used as the representative value of the spectral pattern. However, the TS values were different between the two species and among walleye pollock each month. Therefore, to compare the relative TS spectral shapes, relative frequency responses were calculated by normalizing the mean TS spectra $T S_{\text {mean }}(f)$ by the mean TS values at a nominal frequency expressed in decibels. For example, when normalizing the mean TS value at $70 \mathrm{kHz}, \Delta T S_{70}=T S_{\text {mean }}(f)-T S_{\text {mean }}(70 \mathrm{kHz})$.

\section{Results}

\subsection{TS spectra of standard targets}

The calibration was carried out in each survey; sample results are shown in Fig. 4. The TS spectra of the tungsten carbide spheres measured in April were used for ensuring the quality of our results, as shown below. The individual TS spectra did not change significantly relative to the target position within a $-3 \mathrm{~dB}$ beam width. The TS spectra averaged for approximately 600-1600 single echoes of the spheres are shown in Fig. 5 . When $25 \mathrm{~cm}$ or $40 \mathrm{~cm}$ FFT length was used, similar spectral patterns were obtained and the difference from the predicted TS was almost within $1 \mathrm{~dB}$ over the bandwidth, except in the frequency ranges where the TS values varied noticeably. Meanwhile, the results obtained when using $10 \mathrm{~cm}$ length indicated a larger difference from the predicted TS. In particular, the TS spectra of the $38.1 \mathrm{~mm}$ diameter sphere measured with FM200 kHz included many TS spectra that were obviously lower values than the predicted TS (Fig. 5e). To ensure the data quality and the higher range resolution, $25 \mathrm{~cm}$ FFT length was used for the calculation of the TS spectra. 

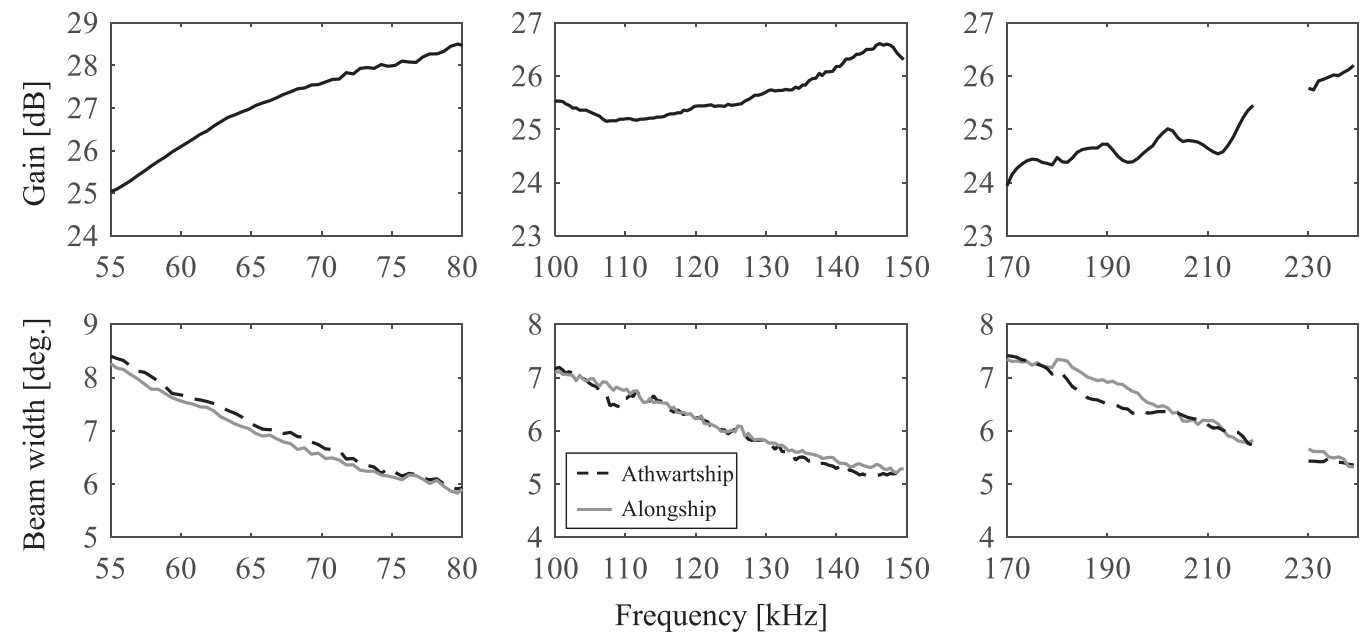

Fig. 4. Transducer gains and beam widths obtained by calibrations. The results in the range $220-230 \mathrm{kHz}$ are missing because the calibration was difficult (Table 2).

\subsection{Evaluation of conditions in measurements of single echoes}

The relationship between $N_{\mathrm{v}}$ and the mean TS values at nominal frequencies are shown in Fig. 6. Increase of the mean TS with $N_{\mathrm{v}}$ can be seen. The TS values of walleye pollock were approximately $2-5 \mathrm{~dB}$ lower than the predicted TS $(-62.3 \mathrm{~dB}$ in April, $-56.8 \mathrm{~dB}$ in May, and $-50.5 \mathrm{~dB}$ in June). $\mathrm{TS}_{\mathrm{cm}}=-66 \mathrm{~dB}$ was generally used to derive the TS at $38 \mathrm{kHz}$, but we used the higher frequencies. In addition, the target walleye pollock was assumed to spend approximately 1-3 months after hatching, estimated from the size of the fish [17], and the growth of their swim-bladder was insufficient, therefore, the predicted TS could be overestimated. Although the overestimation of TS caused underestimation of $N_{\mathrm{v}}$, the TS was stable relative to the $N_{\mathrm{v}}$ except for the dense school layer at 5-8 m depth observed in the measurement on May $9\left(N_{\mathrm{v}}>0.07\right)$. As the TS was obviously higher, the condition was inappropriate to measure the single echoes in the dense layer. Therefore, the single echoes in the layer at $10-15 \mathrm{~m}$ only was used. The $N_{\mathrm{v}}$ of the pointhead flounder was lower than 0.03 for all schools. The predicted TS value was $-47.2 \mathrm{~dB}$ at $70 \mathrm{kHz}$ and $-42.9 \mathrm{~dB}$ at $120 \mathrm{kHz}$, calculated using average $\mathrm{TL}=29.6 \mathrm{~cm}$. Some measured TS were
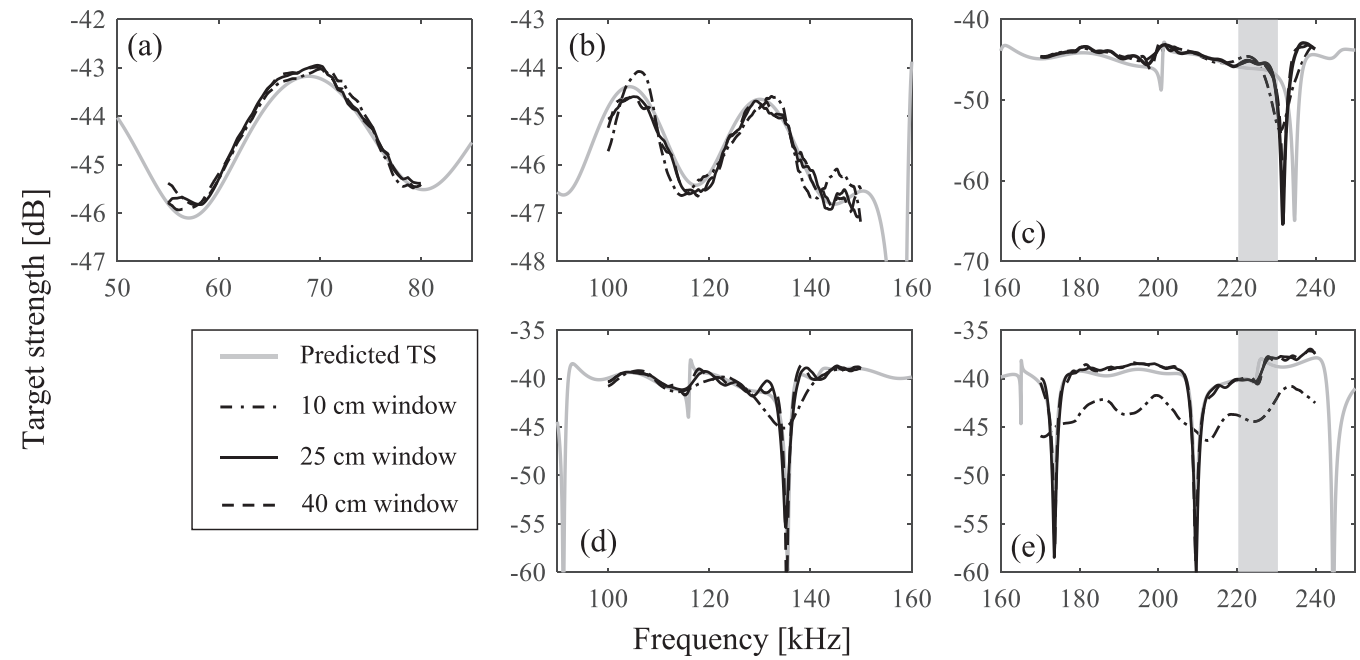

Fig. 5. Target strength spectra of tungsten carbide spheres: (a) $25 \mathrm{~mm}$ diameter sphere, (b) and (c) $22 \mathrm{~mm}$ diameter sphere, and (d) and (e) $38.1 \mathrm{~mm}$ diameter sphere. Gray lines show the theoretical predicted TS spectra, and the others show measured TS spectra, using different FFT window lengths of 10,25 , and $40 \mathrm{~cm}$. 
(a) Walleye pollock

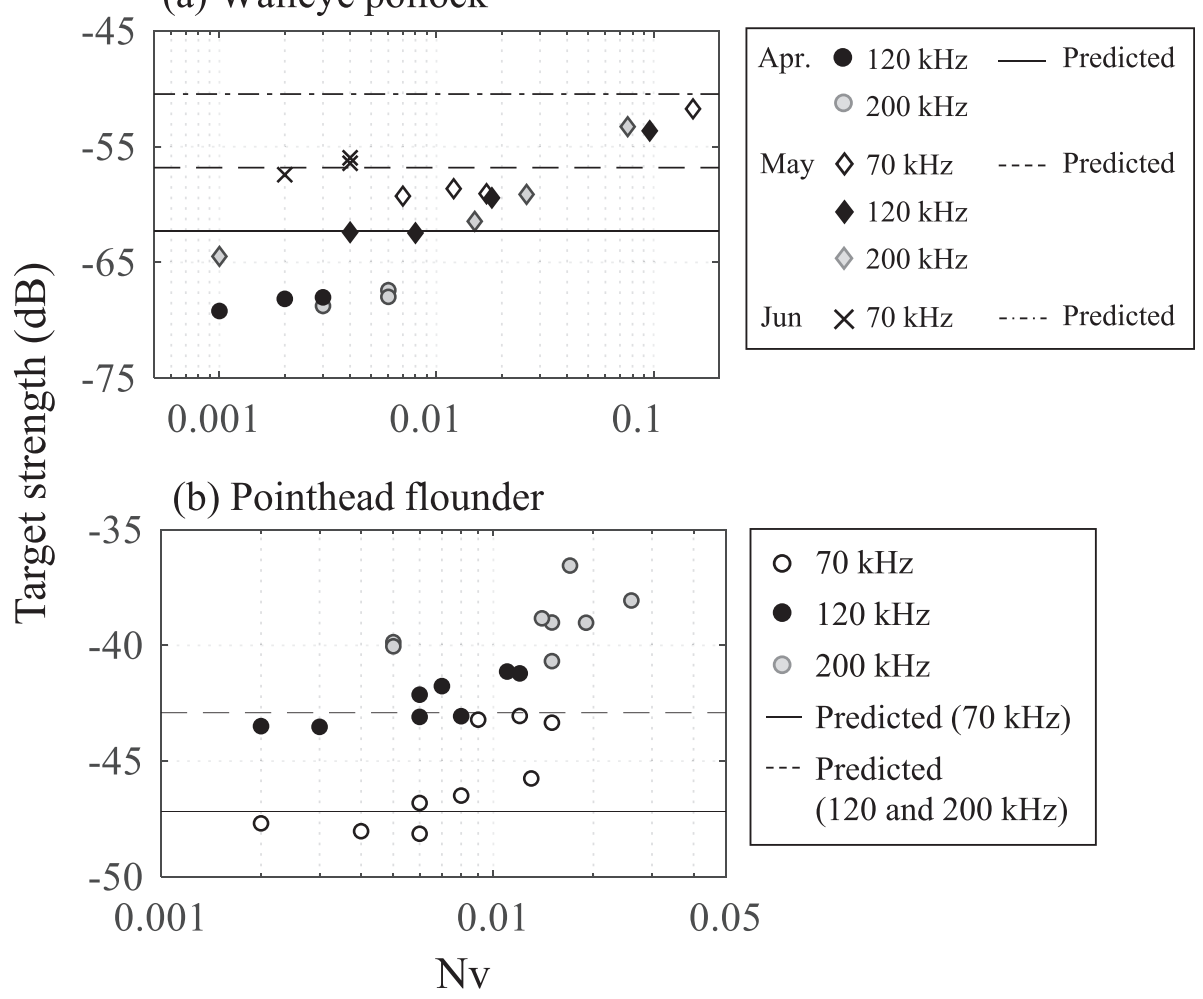

Fig. 6. Relationship between $\mathrm{Nv}$ and target strength at nominal frequencies of (a) walleye pollock and (b) pointhead flounder.

approximately $4 \mathrm{~dB}$ higher than the predicted TS at $70 \mathrm{kHz}$, but the $N_{\mathrm{v}}$ of these data were not noticeably high. The pointhead flounder formed patchy schools, for which $N_{\mathrm{v}}$ could be underestimated if the school had a partial high dense zone within the analysis region of integration [4]. Therefore, the three schools, being TS $>-44 \mathrm{~dB}$ at $70 \mathrm{kHz}$ were considered to have multi-echoes and were excluded for the subsequent analyses. The TS values at $120 \mathrm{kHz}$ were relatively stable and close to the predicted TS. The TS values at $200 \mathrm{kHz}$ were almost stable except for one school that had a higher $\mathrm{TS}=-36.6 \mathrm{~dB}$. That school was not used in the analyses. The TS values at $200 \mathrm{kHz}$ were also higher than those at the other frequencies. They are thought to be affected by the frequency response of the pointhead flounder [18], but we could not obtain confident data for calculation of the predicted TS at $200 \mathrm{kHz}$.

\subsection{TS spectra of juvenile walleye pollock and pointhead flounder}

The single echo number of pointhead flounder and walleye pollock is shown in Table 4 . The TS spectra of the pointhead flounder and walleye pollock were calculated via the single echoes. Figure 7 shows the individual TS spectra calculated from 50 single echoes selected randomly and the mean values of the TS. It had deviations of approximately $10 \mathrm{~dB}$ for walleye pollock and $20 \mathrm{~dB}$ for pointhead flounder at all frequencies. Although

Table 4. Number of single echoes detected in each survey.

\begin{tabular}{|c|c|c|c|c|}
\hline \multirow[t]{2}{*}{ Target species } & \multirow[t]{2}{*}{ Date } & \multicolumn{3}{|c|}{ Number of single echoes at each nominal frequency ${ }^{a}$} \\
\hline & & $70 \mathrm{kHz}$ & $120 \mathrm{kHz}$ & $200 \mathrm{kHz}$ \\
\hline Pointhead flounder & April 12 & $79(1-49)$ & $694(14-330)$ & $531(5-277)$ \\
\hline Walleye pollock & April 12 & & $3571(730-1788)$ & $2717(511-1257)$ \\
\hline Walleye pollock & May 9 & 1612 (524-1612) & $1064(465-1719)$ & $401(401-1286)$ \\
\hline Walleye pollock & June 6 & $8364(2104-3332)$ & & \\
\hline
\end{tabular}




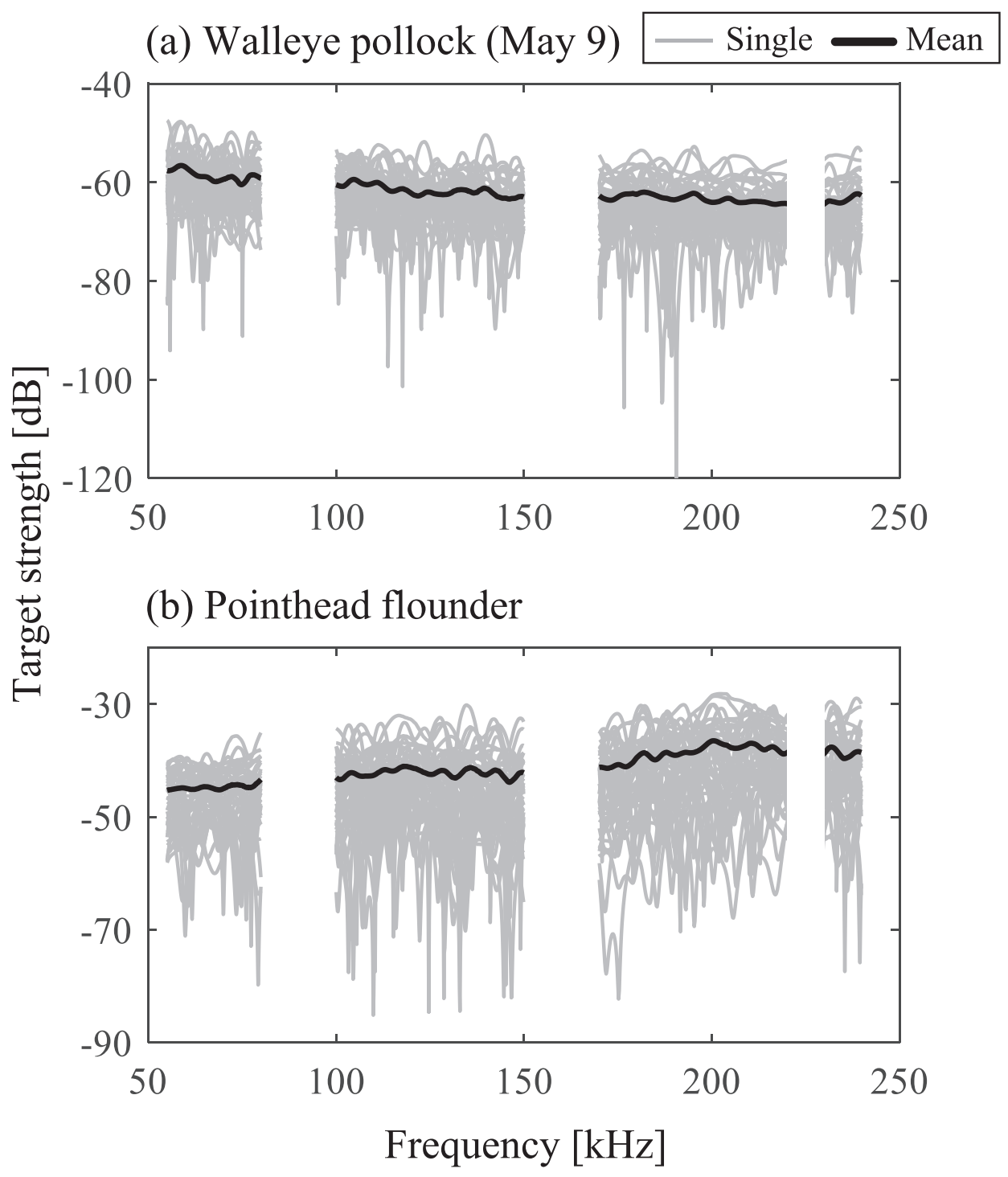

Fig. 7. Target strength spectra of (a) walleye pollock and (b) pointhead flounder. The gray lines show the spectra of 50 single echoes selected randomly by each frequency band, and the black lines show the mean values of the data.

some complex frequency responses including notable peaks and dips were observed in both species, the variation of mean TS relative to the frequency was only a few $\mathrm{dB}$ within each frequency band. The mean TS spectra calculated from all single echoes in each measurement are shown in Fig. 8. The TS values of the walleye pollock were different for each month (Fig. 8a). This is because their size increases during this season, which was revealed by the capture results: the mean FL was $15.3 \mathrm{~mm}$ in April, $28.8 \mathrm{~mm}$ in May, and $59.9 \mathrm{~mm}$ in June. The walleye pollock exhibited slightly higher TS in the $55-80 \mathrm{kHz}$ band than in the other bands in the measurement on May 9, but the frequency response was relatively stable at over $100 \mathrm{kHz}$. The mean TS spectra of the pointhead flounder were from $-47 \mathrm{~dB}$ to $-38 \mathrm{~dB}$ in all frequency bands, and higher TS was observed at higher frequencies (Fig. 8b).

The walleye pollock exhibited -7 to $-2 \mathrm{~dB}$ of $\Delta T S_{70}$ at over $100 \mathrm{kHz}$ (Fig. 9). The pointhead flounder had different characteristics from the walleye pollock, exhibiting $2-4 \mathrm{~dB}$ of $\Delta T S_{70}$ at $100-150 \mathrm{kHz}$, and $2-6 \mathrm{~dB}$ of $\Delta T S_{70}$ at $170-240 \mathrm{kHz}$ (Fig. 9).

\section{Discussion}

\subsection{Quality of the TS data}

Broadband acoustic systems have become widely available owing to recent developments. However, the data processing of broadband acoustic data is 
(a) Walleye pollock

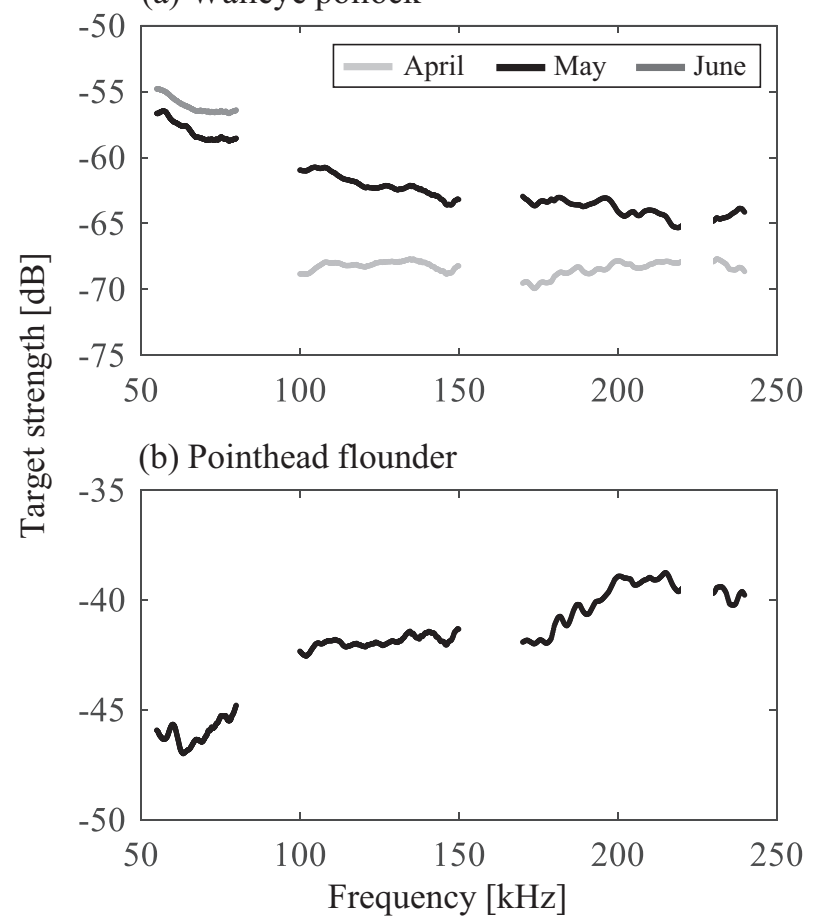

Fig. 8. Mean target strength spectra calculated from single echoes for (a) walleye pollock and (b) pointhead flounder.

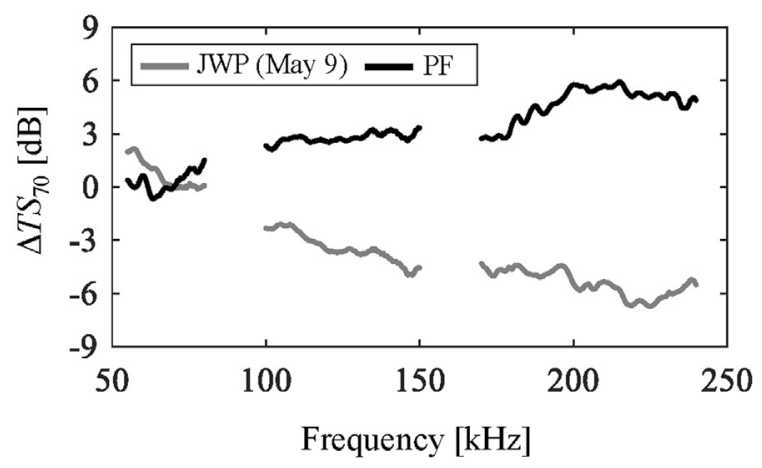

Fig. 9. Comparison of $\Delta T S_{70}$ between juvenile walleye pollock and pointhead flounder at all frequency bands.

currently under discussion. In this study, the data of the tungsten carbide spheres were processed to evaluate the appropriate FFT length and the quality of the data processing. The results indicated that short FFT length $(10 \mathrm{~cm})$ caused incorrect TS spectra (Fig. 5). This result is consistent with that reported by [19]. The longer FFT length also results in degradation of the data due to the inclusion of nontarget echo. As the $25 \mathrm{~cm}$ FFT length could obtain the TS spectral pattern of the spheres close to the predicted spectra by the theoretical calculation, the quality of the broadband acoustic data processing in this study was thought to be ensured.
To judge if the condition is appropriate for extracting single echoes, the index of $N_{\mathrm{v}}$ was used. Increasing TS relative to the $N_{\mathrm{v}}$ was observed (Fig. 6). The predicted TS of pointhead flounder was closer to the measured TS at 70 and $120 \mathrm{kHz}$ if the $N_{\mathrm{v}}$ was lower. The results indicated the $N_{\mathrm{v}}$ was available to evaluate conditions for measuring single echoes. However, the appropriate threshold of $N_{\mathrm{v}}$ could not be determined in this study because the reference data amount was small.

The frequency response of walleye pollock has been reported by some previous studies that measured it in natural conditions with multiple or broadband frequencies $[11,15,18,24]$. These studies showed that the frequency responses of SV have a lower value at lower frequencies. The characteristic of the spectra was also obtained by this study (Fig. 8 and Fig. 9). This characteristic, which is general for fish having a swim-bladder, is affected by the TS variation relative to the tilt angle of the fish [25]. As the variation is larger at higher frequencies, the mean TS becomes lower at higher frequency. On the other hand, the pointhead flounder had higher TS values at higher frequencies, which is congruent with [18]. This has been reported as a characteristic of swim-bladderless fish $[26,27]$. For the swim-bladderless fish, their bones are assumed to mostly affect the characteristic of having a larger TS at a higher frequency [28]. The frequency responses of TS were in good agreement with the previous studies. Therefore, the accuracy of our measured TS is expected to be high.

\subsection{Acoustic discrimination using TS spectra}

The individual TS spectra calculated from each single echo was considered to have various information for acoustic discrimination. The individual TS of the two species had deviations of approximately 10-20 dB (Fig. 7). In general, the in situ TS varied mainly by the size distribution and the fish orientation relative to the incident angle of the acoustic signal. The individual TS spectra obtained in this study were affected by these conditions. The TS of the pointhead flounder had a higher deviation than the walleye pollock. The fish size was thought to be an important factor for the difference in the characteristic. The TS relative to the tilt angle largely varies for larger fish in general. The directivity of the pointhead flounder was assumed to be sharper than the walleye pollock and the TS was easily varied by their swimming angle.

Morphological factors also determine the TS pattern. The swim-bladder of fish critically contributes to the backscattering amplitude [29]. The TS spectral pattern of the walleye pollock is largely 
affected by the swim-bladder. As swim-bladderless fish like pointhead flounder do not have a strong scattering element, the backscattering of the fish is affected by various body tissues. Although the individual TS spectra include such important information for the acoustic discrimination, advanced algorithms would be necessary to isolate the information in detail from the individual TS spectra.

The mean TS measured in situ is also useful to research the average characteristic of targets including the size distribution and the angle distribution. Therefore, the mean TS spectral patterns were used for acoustic discrimination analysis in this study. The mean TS spectra calculated from all single echoes exhibited obvious differences in acoustic characteristics between the two species (Fig. 9). The difference in the broadband relative frequency response is available to discriminate between the two species as it is in the multi-frequency method. If multiple broadband frequencies are available, an obvious difference can be observed. In addition, it is possible for the broadband systems to discriminate using a single broadband frequency in some cases. The $\Delta T S_{70}$ at $55-80 \mathrm{kHz}$ showed different spectral patterns between the two species, which indicated that the two species could be discriminated with only the $\Delta T S_{70}$. This is the advantage of the broadband system. TS values also enable estimation of the size of fish in schools, which is not available for SV. However, the discrimination between species with similar characteristics using the frequency responses of mean TS is uncertain. Thus, another algorithm should be considered for this discrimination, such as a machine learning algorithm. The measurement of broadband in situ TS is also effective for collecting training data for the discrimination.

\section{Acknowledgments}

This work was supported by the Sasakawa Scientific Research Grant from The Japan Science Society (Research number: 2019-6032) and JSPS KAKENHI Grant Number JP19K15891. We would like to thank the captain and crew of T/S UshioMaru for their kind assistance during the surveys.

\section{References}

[1] Simmonds J, MacLennan D. Fisheries acoustics, theory and practice. 2nd ed. UK: Blackwell Publishing Company; 2005.

[2] Peña H. In situ target-strength measurements of Chilean jack mackerel (Trachurus symmetricus murphyi) collected with a scientific echosounder installed on a fishing vessel. ICES (Int Counc Explor Sea) J Mar Sci 2008;65:594-604.

[3] Soule MA, Barange M, Hampton I. Evidence of bias in estimates of target strength obtained with a split-beam echo- sounder. ICES (Int Counc Explor Sea) J Mar Sci 1995;52: 139-44.

[4] Sawada K, Furusawa M, Willamson NJ. Conditions for the precise measurement of fish target strength in situ. J Mari Acoust Soci Japan 1993;20:73-9.

[5] Ona E, Barange M. Methodology for target strength measurements. ICES (Int Counc Explor Sea) Coop Res Rep 1999; 235:28-43.

[6] Demer DA, Soule MA, Hewitt RP. A multiple-frequency method for potentially improving the accuracy and precision of in situ target strength measurements. J Acoust Soc Am 1999;105:2359-2376.

[7] DuFour MR, Mayer CM, Kocovsky PM, Qian SS, Warner DM, Kraus RT, et al. Sparse targets in hydroacoustic surveys: balancing quantity and quality of in situ target strength data. Fish Res 2017;188:173-182.

[8] MacLennan DN, Holiday DV. Fisheries and plankton acoustics: past, present and future. ICES (Int Counc Explor Sea) J Mar Sci 1996;53:513-6.

[9] Kloser RJ, Ryan T, Sakov P, Williams A, Koslow JA. Species identification in deep water using multiple acoustic frequencies. Can J Fish Aquat Sci 2002;59:1065-77.

[10] Korneliussen RJ, Ona E. An operational system for processing and visualizing multi-frequency acoustic data. ICES (Int Counc Explor Sea) J Mar Sci 2002;59:293-313.

[11] De Robertis A, McKelvey D, Ressler PH. Development and application of empirical multi-frequency methods for backscatter classification. Can J Fish Aquat Sci 2010;67:1459-1474.

[12] Chu D, Stanton TK. Application of pulse compression techniques to broadband acoustic scattering by live individual zooplankton. J Acoust Soc Am 1998;104:39-55.

[13] Ehrenberg JE, Torkelson TC. FM slide (chirp) signals: a technique for significantly improving the signal-to-noise performance in hydroacoustic assessment systems. Fish Res 2000;47:193-9.

[14] Stanton TK, Chu D, Jech JM, Irish JD. New broadband methods for resonance classification and high-resolution imagery of fish with swimbladders using a modified commercial broadband echosounder. ICES (Int Counc Explor Sea) J Mar Sci 2010;67:365-78.

[15] Bassett C, De Robertis A, Wilson CD. Broadband echosounder measurements of the frequency response of fishes and euphausiids in the Gulf of Alaska. ICES (Int Counc Explor Sea) J Mar Sci 2017;75:1131-1142.

[16] Blanluet A, Doray M, Berger L, Romagnan J-B, Le Bouffant N, Lehuta S, et al. Characterization of sound scattering layers in the Bay of Biscay using broadband acoustics, nets and video. PloS One 2019;14.

[17] Honda S, Oshima T, Nishimura A, Hattori T. Movement of juvenile walleye pollock, Theragra chalcogramma, from a spawning ground to a nursery ground along the Pacific coast of Hokkaido, Japan. Fish Oceanogr 2004;13:84-98.

[18] Yan N, Mukai T, Yamamoto J, Hasegawa K. Acoustic discrimination between juvenile walleye pollock and pointhead flounder. Fish Res 2020;224.

[19] Demer DA, Andersen LN, Bassett C, Berger L, Chu D, Condiotty J, et al. Evaluation of a wideband echosounder for fisheries and marine ecosystem science. ICES (Int Counc Explor Sea) Coop Res Rep 2017;336.

[20] Lavery AC, Bassett C, Lawson GL, Jech JM. Exploiting signal processing approaches for broadband echosounders. ICES (Int Counc Explor Sea) J Mar Sci 2017;74:2262-75.

[21] Foote KG, Knudsen HP, Vestnes G, MacLennan DN, Simmonds EJ. Calibration of acoustic instruments for fish density estimation: a practical guide, vol. 144. ICES Cooperative Research Report; 1987.

[22] Demer DA, Berger L, Bernasconi M, Bethke E, Boswell K, Chu D, et al. Calibration of acoustic instruments. ICES cooperative research report 326. 2015.

[23] Traynor JJ. Target-strength measurements of walleye pollock (Theragra chalcogramma) and Pacific whiting (Merluccius productus). ICES (Int Counc Explor Sea) J Mar Sci 1996;53: 253-8. 
[24] Woillez M, Ressler PH, Wilson CD, Horne JK. Multifrequency species classification of acoustic-trawl survey data using semi-supervised learning with class discovery. J Acoust Soc Am 2012;131:184-90.

[25] Furusawa M, Amakasu K. Proposal to use fish-length-towavelength ratio characteristics of backscatter from fish for species identification. The Journal of the Marine Acoustics Society of Japan 2018;45:183-196.

[26] Jech JM, Lawson GL, Lavery AC. Wideband (15-260 kHz) acoustic volume backscattering spectra of Northern krill (Meganyctiphanes norvegica) and butterfish (Peprilus triacanthus). ICES (Int Counc Explor Sea) J Mar Sci 2017;74:2249-61.
[27] Scoulding B, Gastauer S, MacLennan DN, Fassler S, Copland P, Fernandes PG. Effects of variable mean target strength on estimates of abundance: the case of Atlantic mackerel (Scomber scombrus). ICES (Int Counc Explor Sea) J Mar Sci 2017;74:822-31.

[28] Gorska N, Korneliussen RJ, Ona E. Acoustic backscatter by schools of adult Atlantic mackerel. ICES (Int Counc Explor Sea) J Mar Sci 2007;64:1145-51.

[29] Foote KG. Importance of the swimbladder in acoustic scattering of fish: a comparison of gadoid and mackerel target strengths. J Acoust Soc Am 1980;67:2084-9. 